\title{
FORTALEZA E TEMPERANÇA SEGUNDO TOMÁS DE AQUINO
}

\author{
FORTALEZA Y TEMPLANCIA SEGÚN TOMÁS DE AQUINO
}

Ronivon Plotasio Amorim*

\begin{abstract}
RESUMO
O presente trabalho pretende compreender, a partir da leitura e reflexão crítica dos textos de Tomás de Aquino, a atividade das virtudes humanas no homem. A virtude adquirida por meio dos bons hábitos constitui o aperfeiçoamento das atitudes humanas para o agir correto, conforme a regra da reta razão. Classificadas como humanas, as virtudes são adquiridas ou infusas. As virtudes cardeais e morais são aquelas que abrem a porta para todas as outras virtudes, elas são denominadas principais por serem as geradoras das outras virtudes. A prudência, a justiça, a fortaleza e a temperança são classificadas como cardeais e morais. A primeira constitui a reta razão do agir, ou seja, dispõe a razão e o discernimento para a escolha do bem e como melhor realizá-lo. A segunda, por sua vez, denomina toda retidão que ajusta os atos humanos, dando a harmonia e promovendo a igualdade em prol das pessoas e do bem comum. A terceira promove a constância da alma e tranquiliza o homem praticante diante do ataque de qualquer mal e dos perigos de morte além de equilibrar as paixões do irascível. Por último, a temperança é a virtude que modera a fascinação pelos prazeres do concupiscível procurando o equilíbrio no uso dos domínios.
\end{abstract}

PALAVRAS-CHAVE: Virtudes. Prudência. Irascível. Concupiscível. Fortaleza. Temperança.

\section{RESUMEN}

El presente trabajo pretende comprender a partir de la lectura y reflexión crítica de los textos de Tomás de Aquino, la actividad de las virtudes humanas en el hombre. La virtud adquirida a través de los buenos hábitos constituye la mejora de las actitudes humanas para actuar correctamente, según la regla de la recta razón. Clasificadas como humanas, las virtudes se adquieren o se infunden. Las virtudes cardinales y morales son las que abren la puerta a todas las demás virtudes, se les llama principales porque son las generadoras de otras virtudes. La prudencia, la justicia, la fortaleza y la templanza se clasifican en cardinales y morales. La primera constituye la razón justa para actuar, es decir, da razón y discernimiento para elegir el bien y la mejor forma de hacerlo. El segundo, a su vez, llama a toda rectitud que ajuste los actos humanos, dando armonía y promoviendo la igualdad a favor de las personas y el bien común. El tercero promueve la constancia del alma y tranquiliza al practicante ante el ataque de cualquier mal y los peligros de la muerte, además de equilibrar las pasiones del irascible. Finalmente, la templanza es la virtud que modera la fascinación por los placeres del concupiscible, buscando el equilibrio en el uso de los dominios.

PALABRAS CLAVE: Virtudes. Prudencia. Irascible. Concupiscible. Fortaleza. Templanza.

\footnotetext{
*Graduado em Filosofia pela PUC Minas. E-mail: ronivon-amorim@hotmail.com.
} 
Este trabalho tem como objetivo apresentar e analisar as virtudes da fortaleza e da temperança a partir das Questões disputadas e da Suma teológica de Tomás de Aquino, juntamente com a prudência e justiça. As virtudes da fortaleza e da temperança são consideradas por Tomás de Aquino como virtudes cardeais e morais, sobre as quais se fundamenta a vida humana em sua conduta. Na tentativa de buscar uma compreensão das virtudes e do seu funcionamento nas ações humanas, abordaremos separadamente alguns aspectos fundamentais.

A presente pesquisa teve como objetivo principal: identificar a importância das virtudes da fortaleza e da temperança respectivamente na educação das paixões do irascível e do concupiscível. E como objetivos específicos: demonstrar as potências sensíveis da alma em que se situam os apetites concupiscível e irascível; identificar a característica emocional e passiva das paixões; caracterizar o registro do domínio das paixões como orientador da vida virtuosa.

\section{VIRTUDE}

A virtude é uma inclinação habitual, estável, para realizar facilmente uma operação benéfica, com agrado. A virtude é certa perfeição da potência, como boa disposição para atingir o ato, como "boa disposição do perfeito para o ótimo" (De virtutibus, q.1, a.1). Assim, a virtude tem uma fundamental função no que se refere o hábito.

Tomás de Aquino distingue alguns tipos de virtudes como intelectuais, teologais, cardeais e morais. Entre as virtudes cardeais e morais, por exemplo, se encontram as virtudes da fortaleza e da temperança. A virtude implica uma certa perfeição do intelecto, ela é uma qualidade ao modo de hábito e ela "é do homem enquanto homem" (De virtutibus, q.1, a.2). Ou seja, a virtude está presente no homem enquanto nos demais animais essa virtude não se expressa. Isso significa que a perfeição do intelecto também é para o homem.

\section{DAS VIRTUDES DA FORTALEZA E DA TEMPERANÇA}

Virtudes cardeais são sinônimos de virtudes morais, pois segundo o Aquinate é a reta razão do agir de modo tanto geral como particular, pois sem a reta razão não pode existir virtude moral; "julgar e decidir bem, o que é próprio da Prudência. [...] a virtude moral não pode existir sem a Prudência" (TOMÁS DE AQUINO, STh Ia IIae, q. 58. A.4). Assim, esta 
virtude é essencial nas existências das demais virtudes morais, especialmente a fortaleza e a temperança.

Após compreender o papel fundamental da prudência e sua relação com as demais virtudes morais. Apreendemos que as virtudes da fortaleza e da temperança, sendo entendidas como virtudes cardeais e morais, têm suas formas particulares de ação na educação das paixões, que veremos no decorrer do texto. A temperança teria a função de controlar a paixão quando esta se impele a algo contrário à razão, e a fortaleza faria com que o homem permanecesse firme frente aos desafios da vida, já que a paixão tende a afastá-lo das normalidades da razão como o temor ao perigo ou sofrimento. Assim, "a temperança, muito mais poderá refrear o movimento da audácia nos perigos”. Nesse sentido, “[...] de modo semelhante, quem pode manter-se firme contra os perigos da morte, muito mais pode manterse firme contra as seduções dos prazeres." (TOMÁS DE AQUINO, Questões Disputadas, q.5, art. 1). Portanto, o exercício da virtude faz o homem forte para viver bem.

As virtudes da temperança e da fortaleza são relativas às próprias paixões. A temperança é o autocontrole, autodomínio, moderação e renúncia. Ela é responsável por ordenar os afetos, domesticar e moderar os impulsos, sublimar as paixões, organizar a sexualidade, moderar os apetites, os quais serão expostos no decorrer deste trabalho. A temperança é a porta de entrada para a vivência da continência, castidade, sobriedade e desapego. É uma das habilidades da virtude da temperança o cuidado do indivíduo para com ele mesmo e com os demais e, de modo singular, com a natureza. Sem renúncia não há maturidade. A temperança não admite que as pessoas sejam escravas, mas sejam livres e libertas para a constância e a maturidade humana. Um dos frutos da renúncia a partir da temperança é a grande satisfação da qual alcança o indivíduo, estampada na alegria e na paz.

A fortaleza torna os homens mais fortes no bem e no amor. Faz com que os homens sejam mais fortes frente às dificuldades do dia a dia, dando-lhes perseverança nas coisas difíceis e árduas da vida. A fortaleza também leva os homens a resistirem a toda mediocridade, a prevenirem-se e evitarem omissões. Por meio da virtude da fortaleza o homem vence a apatia, a acomodação e abraça os desafios da vida cotidiana.

\section{OS APETITES: POTÊNCIAS SENSÍVEIS}

Os apetites são inclinações naturais do ser humano. Tomás de Aquino compara os apetites ao fogo, que tende a se direcionar para cima. Nesse sentido, segundo o filósofo, o 
fogo por meio de sua forma, se direciona para um lugar superior e tende a gerar um semelhante a si. Assim, as paixões e os apetites se assemelham ao fogo.

Quanto às paixões, é importante destacar que elas são movimentos privados, pertencentes à potência sensitiva. Quanto às potências, existem três fundamentais. São elas: intelectiva, sensitiva e vegetativa. Essas são as faculdades da alma, entendidas por movimentação admissível do ser humano. E ainda para esclarecer um pouco o pensamento de Aquino sobre as paixões, portanto, "se diz que as paixões são afetações" (TOMÁS DE AQUINO, STh Ia IIae, q. 22. a. 1) e que a emoção é aquilo que dá movimento às potências sensíveis da alma. Por isso, o Doutor Angélico as chama também "paixões da alma”.

\section{COMO SE COMPREENDE O IRASCÍVEL E O CONCUPISCÍVEL}

O irascível e o concupiscível são compreendidos como condições do apetite sensitivo. O apetite em si é considerado um tipo de potência genérica, e que contém duas faculdades distintas, porém específicas. Então, o apetite sensitivo é a inclinação consequente ao aprendizado sensitivo, assim como o apetite natural constitui a forma natural, que é necessária à parte sensitiva.

Portanto, o concupiscível está ligado aos desejos carnais, como, por exemplo a luxúria. E o irascível pode ser compreendido como aquele impulso de "vingança" contra tudo aquilo que é nocivo e mau ao sujeito.

\section{A PRUDÊNCIA COMO MEDIANA, VIRTUDE FUNDAMENTAL}

A prudência, conforme o pensamento de Tomás de Aquino, está no gênero das virtudes intelectuais. A prudência caminha com as virtudes da fortaleza, justiça e temperança; logo, relacionam-se entre si. A prudência ainda será, para Tomás de Aquino, o máximo do fundamento entre as virtudes morais para o auxílio no equilíbrio das paixões. Como já dito antes, sem a virtude da prudência não é possível que haja outras virtudes morais, que estão nos apetites sensitivo ou intelectivo, como a temperança, a fortaleza e a justiça. Com efeito, a virtude da prudência faz com que a pessoa julgue equilibradamente o bem humano segundo a singularidade do agir; enquanto o intelecto especulativo se ordena apenas à consideração da verdade. 


\section{AS VIRTUDES MORAIS NÃO PODEM EXISTIR SEM A PRUDÊNCIA}

A função específica das virtudes morais é a de inclinar as potências apetitivas para o bem conveniente com a razão, ou seja, de incliná-las para o que é o fim devido, o bem. Assim, a ética proposta por Tomás de Aquino, em seu tratado sobre a prudência, mostra que "a prudência reside propriamente na razão". Nesse sentido, é missão do prudente auxiliar na ordenação das coisas que necessitam ser feitas no presente, e seu mérito está no fato dessa aplicação contingente, que é a finalidade da razão prática.

\section{A FORTALEZA E A TEMPERANÇA NO EQUILÍBRIO DO IRASCÍVEL E DO CONCUPISCÍVEL}

As virtudes da fortaleza e da temperança, segundo o Doutor Comum, possibilitam a educação das paixões do irascível e do concupiscível pertencentes à natureza racional e, logo, são sujeitos da virtude.

\footnotetext{
É aceito por todos que há algumas virtudes no irascível e no concupiscível, como a temperança no concupiscível e a fortaleza no irascível; mas, nisto está a diferença. Pois, alguns distinguem em duas partes o irascível e o concupiscível: na parte superior da alma, e, por outro lado, na inferior. Com efeito, dizem que o irascível e o concupiscível, que estão na parte superior da alma, enquanto pertencem à natureza racional, podem ser sujeito da virtude; no entanto, aqueles que estão na parte inferior pertencem à natureza sensitiva e do bruto. (TOMÁS DE AQUINO, Questões Disputadas, q. 1, art. 1).
}

A virtude é caminho e instrumento para a felicidade. Contudo, é impossível ser plenamente feliz nesta vida e neste mundo, segundo o Aquinate; só é possível ser plenamente feliz no céu, por meio do auxílio divino, ou seja, pela graça de Deus.

As potências da alma são sujeitos das virtudes, porque a virtude inere à alma mediante a potência. A potência da alma é um sujeito enquanto é sustentada pela alma, que é o sujeito por si; e a virtude está na alma mediante a potência. Assim, uma potência pode ser sujeito de uma virtude enquanto uma virtude está nessa potência, pela qual está na alma. Desse modo, percebe-se que o sujeito da virtude da temperança e das virtudes secundárias relativas a ela é o concupiscível. Enquanto o sujeito da virtude da fortaleza e das virtudes secundárias relativas a ela é o irascível. 
Portanto, a opção pelo tema das virtudes morais da fortaleza e da temperança nasceu da intenção de compreender um pouco mais das virtudes no cotidiano. O estudo desse tema contribui tanto para a formação do conhecimento quanto para a formação humana, já que ele aponta as linhas gerais do pensamento tomista na sua visão sobre as virtudes, que estão presentes na vida e no agir humano. E ainda, Tomás de Aquino oferece uma interpretação do que seriam as virtudes, sobretudo o grupo das cardeais e morais, e de como podem ser adquiridas e praticadas para a convivência individual e coletiva das pessoas.

Por fim, mas não menos importante, temos que a ação da virtude provoca a perfeição no ser humano, uma vez que a virtude é uma qualidade totalmente boa, e porque também toda a sua finalidade é direcionada para o bem. Assim, as virtudes são o percurso que um homem, ao buscar uma vida de excelência, deve seguir: elas são como que bússolas para a vida humana. De modo que a conduta eticamente orientada pode ser efetivada na vida pela busca da virtude, que tem como o seu fim a felicidade do homem.

\section{REFERÊNCIAS}

TOMÁS DE AQUINO. As virtudes morais - Questões disputadas sobre a virtude. Tradução Paulo Faitanin e Bernardo Veiga. Campinas, SP: Eclesiae, 2012.

TOMÁS DE AQUINO. Suma teológica. II Seção da II Parte, Introdução e notas das virtudes teologais por Antonin-Marcel Henri e da prudência por Albert Raulin. São Paulo: Loyola, 2004. 